\title{
Squamous cell carcinoma arising in a pilonidal sinus presenting with the formation of an abscess
}

\author{
N. V. JAMIESON \\ M.A., M.B., B.S. \\ T. B. GOODE \\ M.A., B.M., B.Ch. \\ Addenbrooke's Hospital, Cambridge and Bedford General Hospital, Bedford
}

\begin{abstract}
Summary
A case of squamous cell carcinoma arising in a pilonidal sinus and presenting with abscess formation is described and the treatment is discussed.
\end{abstract}

\section{Introduction}

Malignancy arising in a pilonidal sinus is extremely uncommon. In a series of 86,333 pilonidal sinuses treated in the American Armed Forces in the Second World War no malignancies were encountered (Denning et al., 1954). Thirty-four tumours arising in association with pilonidal sinuses have been reported; 29 of these were squamous cell carcinomas and 2 were mixed basal and squamous cell carcinomas.

We report here a squamous cell carcinoma arising in a pilonidal sinus which presented with abscess formation.

\section{Case report}

A 63-year-old engineer presented with a history of a pilonidal sinus in the natal cleft, which had been present for 20 years. There was a 3 month history of a swelling beneath the site of the sinus, which had been increasing slowly in size together with a persistent purulent drainage from the sinus. A similar abscess in his natal cleft 15 years previously had discharged spontaneously and the sinus had been quiescent in the intervening years. Examination revealed an $8 \times 6$ $\mathrm{cm}$ fluctuant mass lying in the natal cleft with 3 sinuses opening to the surface over the mass. There was no visible ulceration and no inguinal lymphadenopathy. Culture of the discharge from the lowest sinus track revealed a mixed growth of coliform organisms.

The abscess cavity and sinus were excised complete with an ellipse of skin and subsequent histological examination revealed a moderately differentiated squamous cell carcinoma (Fig. 1).
The resulting defect slowly healed by granulation but at 3 months a small recurrence was noted and a wide excision performed, which included the coccyx. Once again the defect healed slowly, but after 3 months a further localized recurrence occurred. Following a further wide local excision, a course of radiotherapy of 5,400 rad was given in divided doses over 6 weeks.

He remained free of visible tumour for a further 6 months and then developed an ulcerated area overlying the sacrum and a large abscess in the right buttock. The abscess was drained and biopsy of the wall of the cavity showed a moderately differentiated squamous cell carcinoma. At this stage there was still no clinical evidence of metastatic disease. Plain radiographs and isotopic bone scan showed no abnormality. A whole body computed tomographic (CT) scan showed local tumour invading the glutei and levator ani muscles but no evidence of metastases. The possibility of hemicorporectomy was discussed with the patient but he declined further surgery. He died 18 months after his initial presentation. A post mortem examination was not performed.

\section{Discussion}

The most important factor in the incidence of malignancy in pilonidal sinuses appears to be the length of time that the sinus has been present. The average age of presentation is 49 with an average duration of pilonidal disease of 23 years (Philipshen et al., 1981).

The most common presentations are an ulcerating lesion (Philipshen et al., 1981) or an incidental finding at routine histology (Baraldi, 1942).

Successful treatment with wide excision alone (Philipshen et al., 1981) or in combination with adjuvant chemotherapy (Lerner and Deitrick, 1979) has been reported. The resultant skin defect may be filled using rotation flaps (Philipshen et al., 1981), 


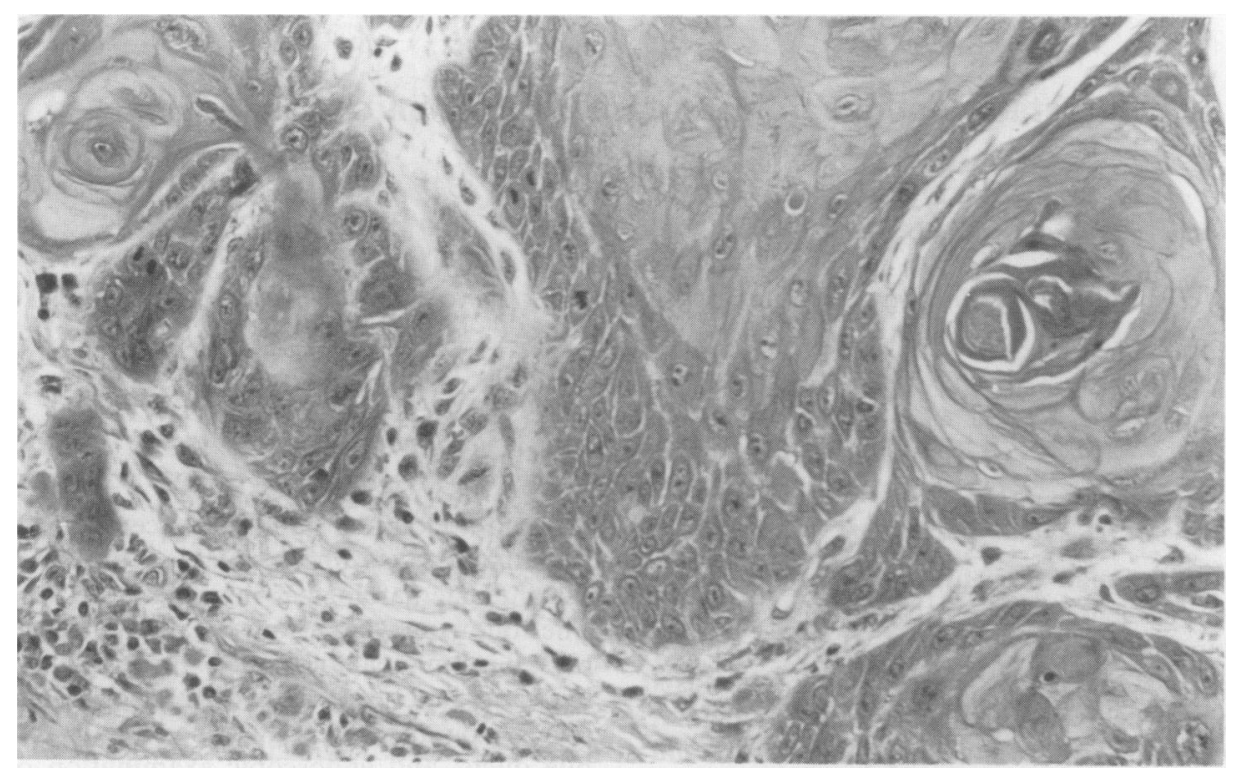

FIG. 1. Squamous cell carcinoma arising in a pilonidal sinus. Magnification H.E. $\times 250$.

split skin graft (Lerner and Deitrick, 1979) or simply left to heal by granulation, as in our case.

Insufficient information is available to assess the place of chemotherapy and radiotherapy. A single patient treated (without surgical excision) with radiotherapy, systemic bleomycin and topical 5-fluoracil had only partial regression of the tumour and died at 7 months with widespread metastatic disease (Yamada and Osata, 1972).

Initial biopsy to confirm the diagnosis should be followed by wide local excision using frozen section to confirm adequate clearance of tumour. CT scanning may be useful in indicating the extent of the local disease and detecting any metastatic spread. A case can be made for postoperative radiotherapy from our own experience of local recurrence following apparently complete excision, which was presumably due to undetected microscopic spread.

Where possible, pilonidal sinuses should be excised early in their history and all excised tissue submitted to histological examination. If healing is delayed after excision the possibility of malignancy must be considered and biopsy performed.

\section{Acknowledgments}

With thanks to Mr J. I. H. Hadfield for permission to report a patient under his care, to Dr J. C. Valentine who provided the photomicrograph,, and to Miss A. Jones for typing the manuscript.

\section{References}

BARALDI, A. (1942) Degeneracion cancerosa de un quiste sacrocoxigeo. Boletines de la Sociedad de cirugia de Rosario, 9, 103.

Denning, J.S., Frederich, J.F., Gold, D. \& PoTH, E.J. (1954) Pilonidal disease: review of the literature and method of closure. American Surgeon, 20, 1250.

LERNER, H.J. \& DEITRICK, G. (1979) Squamous cell carcinoma of the pilonidal sinus: report of a case and review of the literature. Journal of Surgical Oncology, 11, 177.

Philipshen, S.J., Gray, G., Goldsmith, E. \& Dineen, P. (1981) Carcinoma arising in pilonidal sinuses. Annals of Surgery, 193, 506.

YAMADA, M. \& OSATA, S. (1972) A case of squamous cell carcinoma arising in a pilonidal sinus. Japanese Journal of Dermatology, 82, 307. 